This is a peer-reviewed, accepted author manuscript of the following article: Allan, G. J., Connolly, K., \& McIntyre, S. G. (2020). Developing an electricity satellite account (ELSA): an application to Scotland, UK. Economic Systems Research. https://doi.org/10.1080/09535314.2020.1754166

\title{
Developing an Electricity Satellite Account (ELSA): an application to Scotland, UK
}

\author{
Grant Allan ${ }^{\mathrm{a}}$ Kevin Connolly* and Stuart McIntyre \\ ${ }^{a}$ Fraser of Allander Institute, Department of Economics, University of Strathclyde, \\ Glasgow, UK; \\ *corresponding author: Strathclyde Business School, 199 Cathedral Street, Glasgow, \\ UK, G4 0QU. K.connolly@strath.ac.uk
}

\begin{abstract}
Within the system of national accounts the electricity sector is typically reported as a single entry representing generation, transmission, distribution and trade. The ways in which these components interact with the economy differ greatly, a feature lost within the standard accounting framework. In this paper we propose an Electricity Satellite Account (ELSA) approach to better understand the linkages between the electricity sector and economy, with a particular focus on generation technologies. In developing this framework, we draw parallels with Tourism Satellite Accounts (TSAs). To illustrate the practical steps in constructing ELSAs, we develop an ELSA for Scotland for 2012, and show how the ELSA framework gives an improved understanding of the economic contribution of the electricity sector, which is critical in improving the usefulness of such accounts for climate, energy, and economic policy.
\end{abstract}

Keywords: electricity sector; satellite accounts; system of national accounts.

Funding: This work was supported by the ESPRC, under Grant reference [EP/G037728/1] and EPSRC SUPERGEN Wind Programme, under Grant reference [EP/L014106/1].

Acknowledgements: The authors are extremely grateful to two anonymous reviewers for their helpful comments. 


\section{Introduction}

The electricity sector is big business. In the United Kingdom (UK), it contributed 1.2\% to Gross Domestic Product (GDP) in 2018, support $£ 11.5$ billion of investment, and employed over 92,400 (BEIS, 2019a). Despite this, national economic accounts contain only limited information on this important sector. UK national accounts, prepared in line with international conventions for the construction of system of national accounts (SNAs), report one entry for an aggregate "Electricity: generation transmission, distribution and trade" sector (ONS, 2018). As a result of this treatment as a single sector/activity, two important aspects are omitted.

First, no economic distinction is made about the generation, transmission, distribution, or supply activities within this sector. For instance, supply activities, such as managing customers' accounts and billing, will likely have a different labour intensity relative to electricity transmission. It is perhaps also evident that electricity trading activities will be quite different from electricity generation.

Second, it is not possible to identify the heterogeneous economic characteristics between the varied generation technologies used to produce the ultimate product of the sector. Given key differences in the role that each generation technology plays in the electricity market, including producing at different volumes and times, for instance, and the (likely) quite distinct contributions of transmission and distribution activities from generation activities, the current framework is not useful for understanding the economic value and role of the electricity sector.

While it is obvious that different electricity generation methods embody different intensities of employment and greenhouse gas (GHG) emissions, this heterogeneity is lost in national accounts with the presentation of an aggregate electricity sector. This matters as it means that there is no way to understand the relative emissions intensity of each 
generation type (in terms of GHG or CO2 per unit of (financial, £) output . Similarly, low emission electricity generation at a time when the price of electricity is very low, and thus the economic value of that output is low, is less economically valuable than low emission generation at times of high demand and consequently high electricity prices and value. It is only by valuing the different elements of generation - which also takes account of the time dimension of supply and demand - that one can begin to fully understand the progress that is being made in decarbonising the economy.

The coming decades will see significant changes in the electricity sector in the UK, such as the end of coal power generation, ${ }^{1}$ and the expansion of renewable capacity, including offshore wind and solar (BEIS, 2019a). These will produce a host of impacts not only on the energy system, but also on emissions and economic indicators. The lack of detail about the electricity sector available in the national accounts is an impediment to understanding the economic consequences of these changes.

Fortunately, the SNAs have been here before. In 1979 it was recognised that the treatment of tourism activities was unable to reflect the manner in which that sector contributed to the economy. This necessitated the formulation of a methodology to construct Tourism Satellite Accounts (TSAs), led by the World Tourism Organisation. While the parallels are not perfect - some aspects of TSAs are not relevant or important for the electricity sector - in this paper we show that it is both possible to develop a satellite account framework for the electricity sector, and that this sheds important insights into the economic consequences of electricity generation.

There are two main contributions of this paper: first, we develop our "Electricity Satellite Accounts" (ELSA) framework, drawing parallels with commonly used satellite

\footnotetext{
${ }^{1}$ Recently the UK has seen several coal free days, and in May 2019 the UK went two weeks without any coal being used in electricity generation.
} 
accounts for tourism, making clear the gains our framework provides relative to existing representations of the electricity sector in the national accounts. Second, we illustrate the practical steps necessary to construct ELSA, including drawing-in data from the "physical" electricity sector accounts as well as economic sources. We show these steps through the development of an ELSA for Scotland.

Once developed, ELSA can determine key economic aggregates of the electricity sector $^{2}$ including: domestic internal electricity expenditure ( $£ 1.6$ billion in 2012), exported expenditure ( $£ 0.6$ billion), and electricity generation (a contribution to Gross Value Added (GVA) of $£ 1.4$ billion). To our knowledge, an ELSA has not been developed in the literature to date, and the framework and example outlined here develops a new framework to understand the economic contribution that the electricty sector makes.

The rest of the paper proceeds as follows. In Section 2, we review the history of Tourism Satellite Accounts, and their key elements, both to introduce the concept of satellite accounts and as a precursor to developing the ELSA framework. Section 3 outlines the proposed structure of ELSA, discussing the interpretation of each element of the framework and the data which are necessary to complete the Accounts. Section 4 presents our implementation of the ELSA framework for Scotland in 2012, while Sections 5 and 6 provide discuss the usefulness of the insights gained and describes potential extensions of the ELSA framework, respectively. Section 7 concludes, sets out some directions for further refinement of the ELSA method and define future research questions.

\footnotetext{
${ }^{2}$ We use 2012 as the base year for two reasons. First because this is the only year we currently have a Domestic Use table for, and second - and relatedly - because these were the latest available Scottish Input-Output tables when we began this work. More tables have now been released, but these do not include a new Domestic Use table. However, our focus in this paper is developing and illustrating the implementation of our proposed electricity satellite account framework.
} 


\section{Conceptual Satellite Account Framework}

\subsection{History and usefulness of satellite accounts}

The System of National Accounts (SNA), developed following the work of Leontief (1936), are a set of internationally recognised guidelines on developing economic accounts. The structure of these accounts, in order to be versatile and to maximise usefulness, must be generic in nature such that the approach can be readily replicable in other countries and regions. This generic nature does however cause problems in that some aspects of the economy - of economic, political or social importance - are not represented in sufficient detail for policy analysis.

To resolve this, "satellite accounts" were developed, which extended the analysis of certain economic activities alongside the SNA framework. There are two broad categories of satellite accounts: internal and external (Harrison, 2006). Internal satellite accounts expand further on the information found within the SNA framework (for example Tourism Satellite Accounts (hereafter TSAs)). External satellite accounts in contrast (such as environmental ones) add information to the SNAs which are not themselves part of the SNA framework.

The satellite account framework was pioneered through the construction of TSAs $^{3}$. Frenchtling $(1999, \mathrm{p} 1)$ summarises TSAs as a "method of measuring the direct economic contributions of tourism consumption to a national economy". Starting in the 1970s, and gaining greater official attention following the recommendations of the UNWTO (World Tourism Organization) General Assembly in New Delhi in 1983, it was at the UNWTO's International Conference on Travel and Tourism Statistics in Ottawa in 1991 that serious emphasis was placed on constructing TSAs. Since then, through the

\footnotetext{
${ }^{3}$ There are other types of satellite accounts, for example the commuting satellite account developed by Ferreria et al (2018)
} 
UNWTO, but also the OECD and EUROSTAT, there has been a surge in the creation of internationally comparable TSAs (e.g Ragan and Meis. 2016; Ivandić and Marušicś, 2019).

The specific rationale for developing TSAs was that tourism had specific characteristics which could not be captured in conventional SNAs. The activities of temporary residents ("tourists") are fundamentally different from those of permanent residents, based as they are on a: "...temporary situation in which an individual in the capacity of consumer finds himself/herself: he/she is taking a trip or a visit to a place outside his/her usual environment for less than a year and for a purpose other than being employed by a resident entity there. This differentiates a visitor from the other categories of consumers." (Eurostat, 2008, p2). To treat this type of consumer as if they were a permanent resident, would clearly be inappropriate; although this is what traditional SNAs do.

The fundamental issue with tourism in the national accounts is that there is not a single economic activity which constitutes the production of tourism goods, or an entry which relates to the consumption levels of tourism. Tourism expenditure is defined by the characteristics of goods' consumption (e.g. by a visitor away from their home environment) rather than a specific good. Thus, representing the economic scale of the activities associated with tourism is possible via the detail provided by the Tourism Satellite Accounts (which are themselves necessarily consistent to the national accounts within which the tourism activity takes place).

TSAs enable the quantification of macroeconomic aggregates to those found in traditional SNAs, but which are based on the unique characteristics of the tourism economy. Such aggregates include: the Gross Value Added (GVA), gross fixed capital formation and employment contribution of tourism, the (heterogeneous across tourism 
types) nature of consumption in this activity and its links to the use of domestic and overseas goods and services as inputs (Frechtling. 2010; Song et al, 2012). These satellite accounts are descriptive, reporting on the activities of the tourism sector itself (see for example, Frechtling (1999) and Jones and Munday (2010)).

\subsection{Comparing satellite accounts with disaggregation}

In order to try to understand a range of questions about the links between the physical generation activities of the electricity sector and the economic accounts, researchers have often turned to disaggregating Input-Output (IO) accounts. The IO accounts are an important part of the SNA framework - and are multisectoral, providing information on economic activities defined by the industry or sector which best represents the activity undertaken. In the literature so far, a number of studies have disaggregated the (typically, single) electricity generation, transmission and distribution sector into its generation components through bringing in other data on the production activities in the sector.

At its simplest level this involved splitting out the aggregate sector using shares of total generation represented by each technology. This approach is useful in preserving the overall structure and integrity of the set of economic accounts, but implicit in this approach is the strong assumption that there is a uniform electricity price. Yet even with the relaxation of this assumption, this approach - while opening up some new avenues of research - this does not provide much depth of understanding of the economic links of each of these disaggregated generation sectors. To see this more clearly, we will summarise the additional gains obtained from our proposed electricity satellite account approach.

First, the satellite account approach is designed to bring together a wider range of information about the electricity sector beyond that provided in the IO tables. The most 
obvious example of this is information on employment and emissions in each part of the electricity sector.

Second, the satellite account framework enables a much better understanding of the underlying trade in electricity than the standard IO framework. In particular, we will see how imports (and exports) of electricity by generation type and its final (consumption) destination add to our understanding through an electricity satellite account. In a conventional IO disaggregation of the electricity sector, one would simply have the total imports by each generation sector (and consuming sector), and not detailed information on the types of imports, including electricity by generation technology.

Third, using a satellite account we are able to quantify the monetary value of activity in the electricity sector, and hence provide economic parallels to the presentation of information on physical flows of electricity widely reported and commented upon (e.g. BEIS, 2019c).

Fourth, the satellite account approach enables us to capture differences in the timing and level of electricity demand for different types of consumers (specifically industries and households) without also requiring the disaggregation of all final demands for these consumers. In the IO framework to display this information for different consumer types, by end use, we would have to create new final demand vectors for each type of consumer. This would necessitate disaggregating these consumers' demand for the output of all sectors. Not only do we not have the information to do this, beyond making some broad brush assumptions, it is not something that is necessary to understand the sources of demand for different generation types. The satellite account methodology enables us to capture differences in the timing and generation mix underpinning electricity demand for different types of consumers in a self - contained and accessible 
way. All of which is why we believe that the satellite account methodology adds value to our understanding of the economic impact of the electricity sector.

\subsection{Tourism Satellite Accounts as an example of the SA framework}

There are four guiding principles to the construction of TSAs. They can be summarised as: 1) basing estimates on reliable statistical sources; 2) using statistical data that are produced on a continuing basis; 3 ) ensuring the comparability of data within the same country over time and across countries and other types of economic activity, and; 4) ensuring the internal consistency of all data used and comparability with other macroeconomic data (Eurostat, 2008).

A full TSA for a nation or region consists of ten TSA tables, although they can be constructed using as few as seven "core" tables (Frechtling, 1999) ${ }^{4}$. These seven tables provide the core TSA framework. They enable the identification of spending (i.e. consumption) by different types of tourist, making the clear distinction between inbound, outbound and domestic tourists, as well as between day-trippers and other forms of tourist, and the production of the products consumed by tourists in the broader economy. This enables these expenditures to be linked to the jobs that are supported in the economy by this tourism activity, giving a rounded picture of the scale of tourism in the economy with much greater resolution than one would get from the SNA.

\footnotetext{
${ }^{4}$ Three additional tables are often included within a Tourism Satellite Account. The first (referred to as TSA Table 8) captures the link between tourism and investment, with types of investment spending for tourists (e.g. accommodation for visitors, transport for tourism activities, etc.) in the rows and industries in the columns (showing both tourism and non-tourism industries). The second additional table (TSA Table 9) focuses on non-market services (e.g. public tourism promotion services, visitor information services, etc.) by the level of government that provides this service (e.g. national, regional, local). The final table, TSA Table 10, focuses on non-monetary indicators such as the number of tourists and the number of trips, types of accommodation and transport used in the tourism sector.
} 
Figure 1 presents a schematic showing the relationships between the core tables; four on the demand-side (TSA Tables 1 to $4^{5}$ ) and three on the supply-side (TSA Tables 5 to 7). TSA Tables 1, 2 and 3 capture inbound, domestic and outbound tourism expenditures, respectively by product (rows) and type of tourist (columns). TSA Table 4 captures total internal tourism expenditure (i.e. tourist spending made in the nation/region) which adds together elements from TSA Tables 1 and 2.

TSA Table 5 provides a representation of the production of tourism activities at basic prices. This is a product-by-industry representation, showing tourism products (rows) and the industries producing these items (columns). TSA Table 6 is also laid out in a product-by-industry configuration and focuses on total supply of tourism products, reconciling domestic supply with total internal tourism demand by linking into the supply and use tables of the SNA, and indicating the share of domestic supply in the consumption of tourism products. It is denoted in purchasers' prices, and so included taxes on products and distribution margins on tourism products. TSA Table 7 links TSA Table 6 to employment, so that employment in tourism industries can be identified (Eurostat, 2008).

\section{[Insert Figure 1]}

Having outlined the structure of TSAs, it is worth listing the key aggregates that are normally reported (Eurostat, 2008) These are: internal tourism expenditure; GVA of tourism industries; tourism direct GVA; and tourism direct gross domestic product. These

\footnotetext{
${ }^{5}$ To help distinguish between the Tables of the TSA/ELSA, and Tables contained in this manuscript, we refer to "TSA Tables" or "ELSA Tables" rather than table numbers in the manuscript for the rest of this article.
} 
encompass the key elements on the economic health of the tourism economy one would be interested in, but would not know from a conventional SNA ${ }^{6}$.

The data in the TSA enables the user to understand the product and industry nature of tourism consumption, and therefore a framework connecting the economic links between tourism to the rest of the economy. Having an additional table linking to employment clearly adds to the knowledge of the activities of the tourism sector. In the next section, we elucidate the rationale and usefulness of applying this framework (appropriately re-defined) to the electricity industry.

Wider economic impacts - such as indirect or induced effects across the rest of the economy - are explicitly not captured in a TSA, however they can be estimated by linking to methods which use economic accounts as a major input, such as Input-Output (IO) or Computable General Equilibrium (CGE) models (Frechtling, 1999). The creation of an ELSA however, can also improve the detail provided within IO and CGE models through providing data to implement a disaggregation of the electricity sector, as discussed earlier.

\section{An Electricity Satellite Account (ELSA)}

The preceding section summarised a robust, replicable and widely applied framework for reporting the activities of the tourism sector in greater detail than otherwise provided by a SNA. In this section we take each element of this framework and explore its adaptation to provide a similarly improved resolution of the activities of the electricity sector. We begin with a presentation of the overarching framework in Figure 2, paralleling that presented in Figure 1 for TSAs.

\footnotetext{
${ }^{6}$ The latest UK TSA for 2017 (ONS, 2019) calculated internal tourism expenditure to be $£ 149.9$ billion and GVA of tourisms industries of $£ 1,846.7$ billion.
} 


\section{[Insert Figure 2]}

As before, the first four tables focus on demand. In this case, we are considering for a specific period (e.g. a year) the electricity produced outside, but consumed within, a particular nation or region, i.e. imports (ELSA Table 1); the domestic (ownnation/region) consumption of domestically produced electricity (ELSA Table 2) and consumption of electricity produced in the nation/region but consumed outside of that location (so, exports from the area for which the ELSA is being prepared) (ELSA Table $3)$.

TSA Table 4 gives an overview of the total tourism expenditure in the area, which is a combination of inbound and domestic tourism. In the electricity case, it is the domestic and exported activity which is of most interest to the health of the economy, with imports of less interest (beyond obviously ensuring security of supply, and hence preventing economically damaging shortages/outages). ELSA Table 4 therefore aggregates expenditures from ELSA Tables 2 and 3, rather than TSA Table 1 and Table 2 in the $\operatorname{TSA}^{7}$.

The TSA is concerned with total tourism demand in an economic area, which is the sum of imports of tourism demand (TSA Table 1) and domestic tourist demand (TSA Table 2). In the ELSA case, we are interested in the sum of domestic electricity consumption from domestic generation (ELSA Table 2), and domestically produced electricity used outside the area (ELSA Table 3). Within the ELSA framework, each of these tables respectively can be broken down by the technology of generation as the "product" with different potential consumer "types" identified, such as residential,

\footnotetext{
7 We note that in the TSA Table 1 tourists come from abroad and thus the expenditure 'arrives'. In ELSA Table 1 physical electricity 'arrives' but expenditure is being 'sent' to generators outside the area.
} 
business, etc. Thus, these tables provide a detailed understanding of where electricity is produced (and consumed), what technology is being used in its generation, who is consuming the electricity. This is a major advance on what is currently known and reported about the electricity sector in national accounts, and as discussed earlier an enhanced level of detail relative to a simple disaggregation of the IO accounts.

ELSA Table 6 is a direct parallel with TSA Table 6. Here the supply of each product, presented in the production account (ELSA Table 5), is linked to the sector which uses it, and with total internal consumption of the electricity sector (thus includes imports of electricity). In this way, ELSA Table 6 represents total supply and demand of electricity in the national/regional economy. ELSA Table 7 provides data on employment in electricity generation by technology.

Following this setup, we now have a framework which can provide the following information: who is consuming what quantity of domestically produced electricity by generation type ("product") (ELSA Table 2 and ESLA Table 3); who is consuming electricity imports by (non-local) generation type (ELSA Table 1); the total domestic electricity consumption by type of generation and consumer (ELSA Table 4); the production of each product by each industry in the domestic economy (ELSA Table 5); the domestic supply and use of each product in the economy by sector (ELSA Table 6); and the level of employment by electricity generation type (ELSA Table 7). Doing this enables the calculation of a range of macroeconomic aggregates related to the electricity sector, just as in the TSA.

In this section we have set out the structure of ELSA and explored the parallels between an electricity and a tourism satellite account. The ELSA framework is readily replicable internationally both at national and regional levels. In the next section we illustrate the construction of an ELSA for Scotland. 


\section{Creating an electricity Satellite Account for Scotland}

In this section we discuss the implementation of the ELSA approach. We begin by providing some information about the electricity sector in Scotland, so that the reader has some familiarity with electricity issues in this application.

\subsection{Electricity in Scotland}

In 2012 , almost $30 \%$ of total electricity generation in Scotland was from renewable technologies; the remaining non-renewable generation included 34\% from nuclear, $25 \%$ from coal, $8 \%$ from gas and 3\% from oil. Comparing gross electricity generation, with gross 'domestic' (i.e. Scottish) electricity consumption, led the Scottish Government to state that the equivalent of $40.3 \%$ of consumption in Scotland in 2012 came from Scottish renewable sources, against its target of the equivalent of $100 \%$ of Scottish consumption by 2020 (Scottish Government, 2018).

It is important to note that these 'equivalent' targets do not imply that all Scottish consumption of electricity will be met from domestically-located facilities. In particular, with a Scottish generation mix increasingly producing electricity from renewable technologies, and with Scotland being part of a Great Britain (GB)-wide electricity grid, there is no requirement that Scottish demand and supply are equal. Put differently, there are many times when Scottish electricity consumption is met by imports of electricity from the rest of the UK (and also when there will be exports from Scotland when Scottish generation is in excess of Scottish demand). Indeed between 2012 and 2017, electrical imports rose by $108 \%$, with exports also rising by $68 \%$ in the same period (BEIS, $2018 \mathrm{~b}$ ).

The level of electricity trade between Scotland and the rest of the GB system will be directly affected by the generation mix in Scotland. For instance, the closure of Longannet coal power plant in 2016, has caused the number of half hour time periods 
when Scotland is importing electricity to slightly increase. But to understand the economic implications of these changes we need to know when the electricity is being imported, and the electricity price at that time. As the generation mix changes, Scotland could see itself exporting more electricity to the rest of GB, but seeing its economic trade balance in electricity worsen as it imports more electricity at peak periods when the price is high, and less (or none) when the price is low.

This matching of supply and demand at each time step is central to the construction of ELSA. It will enable us to better understand both the economic value of each unit of electricity generated from each technology, but also to quantify the value of imports and exports of electricity from Scotland.

\subsection{The creation of an ELSA for Scotland for 2012}

\subsubsection{ELSA Tables 1 to 4}

As detailed in Section 3, ELSA Tables 1, 2 and 3 denote - in turn - expenditure on electricity produced outside Scotland (imports), domestically-produced electricity consumed in Scotland, and electricity produced in Scotland and consumed outside of Scotland (exports), respectively. These tables are reproduced in reduced form in Appendix A. In order to understand the expenditure of different consumer types on electricity produced using different technologies, one must have information on the time profile of electricity supply by technology, and electricity demand by consumer type.

Our starting point is information on electricity generation, by generation station, to characterise electricity generation (supply) within Scotland by technology. For this we 
use data from the freely downloadable Elexon portal ${ }^{8}$. Elexon is a large database containing a wide variety of information relating to the UK electricity network. From the balance mechanism, we are able to calculate ${ }^{9}$ the physical electricity generation of each power plant connected to the transmission or distribution system within Scotland at halfhourly time periods - the time step at which the UK electricity market operates. This is a key input to ELSA Table 2 and Table 3. For these ELSA tables, however for these tables, we also need to know the sources of demand for electricity in Scotland.

We can initially think of three broad categories of consumption; end use (i.e. within Scotland), pumped storage and losses. End use is by far the largest, and includes a number of different types of consumption (for example households, industry and government). We start by noting that Scottish half-hourly electricity demand is not directly reported, but can be indirectly inferred from information reported within the Elexon portal. Elexon provides data on half-hourly electricity demand for the GB grid along with the England \& Wales grid. In this work, Scottish demand is assumed to be the residual of GB demand minus England \& Wales demand at each time step. Knowing Scottish demand at each time step, we can calculate the electricity generation mix at that time step using the Elexon data, and calculate the volume of electricity used by each category of demand, by the technology used to meet that demand, at each time step. Summing across all 17,568 time steps in 2012 we arrive at the annual total for electricity demand for each generation technology.

Two other entries in Tables 2 and 4 of the ELSA framework deserve further explanation. These relate to the columns for "pumped storage" and "losses". Unlike other forms of generation, pumped hydroelectric stations both sell electricity to, and purchase

\footnotetext{
${ }^{8}$ The data are available from: www.elexonportal.co.uk

${ }^{9}$ We calculate the output (in MWh) of each power plant by combining the Final Physical Notification (BOA) information with the Bid Offer Acceptance (BOA) to arrive at an estimate of the output of each power plant.
} 
electricity from, the transmission network: using electricity to generate electricity from converting potential energy from reservoirs to electrical energy using gravity and then pumping water uphill into the reservoir. To understand the profile of its electricity demand (and the generation mix for its "consumption") we observe when this technology uses electricity, and calculate the share of electricity use by technology in the same way as we do for other types of consumption group $^{10}$.

There are two types of losses in the electrical system: technical and non-technical (Navani et al, 2012). Technical losses stem from the fact that the electrical network is a system which is transporting a form of energy. Most losses are due to resistance where electricity will be lost (in the form of heat) due to friction in the cables. Non-technical losses are mostly caused by elements which are not related to the transportation or transformation of energy, with the most common non-technical loss being due to cable theft. As thefts, as with non-technical losses, are essentially random there is no way to accurately model their associated losses in the grid. Due to this we combine the technical and non-technical losses from BEIS (2016) to estimate losses at each time step based on the proportion of generation at that time step compared to annual generation.

Finally, in terms of imports and exports of electricity (ELSA Table 1 and ELSA Table 3), we proceed as follows: Scotland is part of the GB electricity grid with a direct inter-connector with the rest of GB (i.e. England and Wales) and another with Northern Ireland. This is useful, because we have good information on electricity generation in both of these places. In aggregate these tell us that, over the year, Scotland is a net exporter of electricity. Exports from Scotland to Northern Ireland are known precisely from interconnector data. Applying the Scottish generation share at each time step to the

\footnotetext{
${ }^{10}$ In the Elexon data for Pumped hydro, positive values indicate that the plant is generating electricity whereas negative values indicate that the plant is consuming electricity from the grid (often doing so in order to pump water back into the reservoir).
} 
volume of electricity exported in that time step through the Scottish to Northern Ireland interconnector, we can disaggregate half-hourly (and therefore annual) electricity exports by generation technology.

Electricity exports to the rest of GB, however, are not directly monitored, therefore we must proceed differently. In our case, given the lack of capacity to store electricity, we assume that Scotland does not import electricity when there is a surplus of Scottish generation over Scottish consumption (after taking into account losses, exports to Northern Ireland and use in pumped storage identified earlier). Instead, the surplus is assumed to be exported to the rest of GB. This amount can then be broken down further by technology using the Elexon data as before.

Conversely, when there is a deficit between demand (consumption) and supply (generation plus any imports from Northern Ireland) in Scotland, this deficit must be made up with imports from the rest of GB. From the Elexon data, we know the generation mix at each time-step in the rest of GB, and therefore can apply those generation mix shares to the volume of imported electricity into Scotland.

In summary, using a detailed study of Elexon data for the GB, we can establish the scale and generation mix of domestically used, exported and imported electricity in Scotland in 2012. Aggregating the data over the 17,568 half-hourly time steps in the year produces annual data for ELSA Tables 1,2 and 3. Similarly, as detailed earlier, ELSA Table 4 follows from a summation of elements in ELSA Table 2 and ELSA Table 3.

We outlined earlier that in the Elexon data one finds electricity demand disaggregated according to three categories: "domestic", "pumped storage" and "losses". In order to better understand what is happening in the electricity sector and to link to the economic accounts (for households and different economic sectors), one needs to be able 
to further disaggregate the "domestic" category. In this section we describe our approach to this challenge.

In order to split this estimated aggregate electricity demand into the demands from each type or sector of consumption, there are different approaches that one could take. Some authors (e.g. Filik et al (2009)) use short/long term forecasting models based on linear regression techniques to temporally disaggregate the electricity demand data. Similar approaches have been used for forecasting electricity prices (e.g. Skantze et al (2000)). Other papers disaggregate overall electricity demand into final use through the use of normalised demand profiles (Farinaccio et al (1999), Hesmondhalgh (2012)). The use of normalised demand profiles is the method applied in this paper.

Our first step is to disaggregate these consumption data by time-step according to whether the electricity is being used by households or firms. To do this, we use demand profiles produced by Ofgem (2012) and Elexon (Elexon, 2013). These detail the normalised electricity use by half-hour for different consumers, and are created using one of two main approaches. The first is based on measurement of electricity use over a significant period of time (e.g. as done by Reichmuth (2008)). The second is using specialised software (e.g. Clark et al, 2011) to model electricity demand for different buildings.

The domestic and industrial profiles used for this paper are from Elexon, who provide 10 profiles for the services sectors ${ }^{11}$ identifiable from Ofgem (2012). First we must calculate the overall annual electricity demand for each of these sectors. The Energy in Scotland (2014), which reports on 2012, publication splits overall Scottish electricity

\footnotetext{
${ }^{11}$ These are: offices; communication; education; government; health; hotel; other; retail; sport and warehouses.
} 
consumption into three sectors: households, industrial and services, which we separate further using information from BEIS (2016), again based on 2012 data $^{12}$.

Using the normalised demand profiles, we create a generic year for each of the 12 sectors. This involved combining five generic weekdays (Monday to Friday) followed by a Saturday and Sunday profile to create a full week (the Ofgem profiles do not distinguish between Saturday and Sunday, thus two generic weekend profiles are used instead), and then the application of a set of (four - winter, spring, summer and autumn) seasonal profiles to these weekly profiles. We thus consider that "week to week" these profiles would be an exact replica of the last with the only change in relative demand being when there is a seasonal change.

However, this is clearly not the case in practice, with electrical demand constantly varying and demand for any two days will not be exactly the same (although some will be similar depending on conditions/day of the week, etc.). We account for variation in electricity demand by introducing a variation constant ${ }^{13}$.

$$
\text { Variation Constant }(t)_{i}=\frac{\text { Scottish demand }(t)_{i}}{\text { Average demand }_{i}(\text { Season })}
$$

new normalised output n $_{i}=$ old normalised output $_{i} *{\text { variation } \text { constant }_{i}}$

Appling the normalised constants for each half-hourly interval to each of the sector profiles gives normalised varying annual profiles for the 12 sectors. The electricity output for each sector at each half-hour interval was found using information on the total annual consumption by sector:

\footnotetext{
${ }^{12}$ The assumption made is that the Scottish services sector consumption proportions are the same as the UK as a whole. ${ }^{13}$ The assumption being made here is that sectoral demand varies in the same proportion as overall Scottish demand.
} 
Half hourly demand $(M W h)_{i}$

$$
=\frac{\text { new normalised output }}{\sum \text { new normalised output }} * \text { Sectoral yearly consumption }
$$

\subsubsection{Tables 5-7}

ELSA Table 5, like TSA Table 5, is a production account. The rows of this table are the products of each industry and, in the columns, each of the industries in the economy. For the creation of this table information from ELSA Table 2 and a Scottish Domestic Use table was used. In the physical generation of electricity power plants (especially large scale) will use electricity - which we capture in this production account. For this we use a Products-by-Industry Scottish Domestic Use ${ }^{14}$ table. For all products other than electricity, the rows - showing the sales of each Product by each Industry - are aggregated as they are not relevant for an ELSA.

The single electricity row is separated by generation products (coal, nuclear, wind etc.) which will leave an "other generation activities ${ }^{15}$, transmission, sales etc." sector. The electricity generation by type ("product") rows are filled with information from ELSA Table 2 with regards to domestically used electricity for each of the industries, with the Electricity industry element in this table being generators' own-use. With the product rows accounted for, information has to be included on GVA, which can be obtained from the Scottish Industry-by-Industry (IxI) IO tables (Scottish Government, 2019).

\footnotetext{
${ }^{14}$ The 'domestic use' table was only available to us for a single year, hence our focus here on an ELSA for 2012.

15 Due to the way in which the Scottish IO tables are produced, whereby companies are classified by their primary activity, this product will include non-electricity activities such as gas sales and training. This is not a problem for the generation products as the information in the ELSA, as by using bottom up data, we only include the generation of electricity.
} 
ELSA Table 6 uses the data from ELSA Table 5, but extends it by incorporating exported products from ELSA Table 3 to fully characterize domestic supply of each product. In addition we report the value of taxes less subsidies on those electricity generation products, using information from the $\mathrm{ROC}^{16}$ register ${ }^{17}$.

\section{Results and Discussion of the Scottish ELSA}

The previous section outlined the approach used develop an ELSA for Scotland in 2012. The primary purpose of the development of an ELSA is to improve the analysis of the electricity sector beyond that produced in the SNA framework. In this section we demonstrate the construction of an ELSA, using the example of the Scottish electricity system, to demonstrate the usefulness of the ELSA approach ${ }^{18}$.

Table 1 below gives the value of imports of electricity. Table 1 shows that imported electricity to Scotland in 2012 was dominated by conventional power plants, which would be expected. Penetration levels of renewable technologies are much higher in Scotland than the UK as a whole, thus Scotland needs imports of electricity when these are not available. We can immediately see the usefulness of the ELSA framework as we can identify imported electricity by product, in the same way as TSA Table 1 identifies inbound tourism by product.

[Insert Table 1]

[Insert Table 2]

\footnotetext{
16 The Renewable Obligation Certificate Scheme (ROCs) was introduced in 2002 with the goal of increasing the proportion of renewable electricity on the network in the UK. Under this scheme electricity suppliers must prove that a certain amount of electricity (based on targets) has been generated through renewables source, achieved through the purchase of ROCs (at the set buyout price) from accredited generators (Grimwood and Ares, 2016).

${ }^{17}$ For more information see: https://renewablesandchp.ofgem.gov.uk/

${ }^{18}$ Full tables can be found in Appendix A.
} 
By far the most commonly used form of electricity in Scotland in terms of expenditure is nuclear energy. To be economically viable nuclear power stations must operate at near full capacity at all times and Scotland has two nuclear facilities - a relatively large proportion of nuclear power stations with regards to population size. Scotland has a population of approximately 5.4 million people and 2 nuclear power stations (2.6MW capacity) whereas in England there are 6 nuclear power stations (6.6MW capacity) for a population of 54 million. We estimate that nuclear power was responsible for around $34 \%$ of the total domestic electricity expenditure in Scotland ( $£ 552$ million out of a total of $£ 1603$ million). The second most domestically used electricity (by expenditure) is coal; in 2012 there were two large coal fired power station operating in Scotland. The next table of the Scottish ELSA is the Scottish domestic consumption of electricity (ELSA Table 2).

Within the standard SNA framework this information on the electrical consumption (by sector and value) is not available. ELSA Table 2 of the ELSA framework allows us to see expenditure on electricity generation by technology and where it is being used ${ }^{19}$.

[Insert Table 3]

One of the most interesting figures when comparing Tables 2 and 3 of the Scottish ELSA is the expenditure of domestically used ( $£ 240$ million) and exported ( $£ 120$ million) wind energy. One-third of the total expenditure on electricity generated by wind power comes from selling it to the rest of Great Britain (i.e. exports) - something that is not

\footnotetext{
19 We assume, as Scotland is only physically connected to Northern Ireland and England \& Wales, that all ROW exports are non-generation output. In futures as interconnectors are added these ROW exports can be separated using a similar methods as the NI interconnector.
} 
shown in the standard SNA framework. This is due to the fact that wind is a nondispatchable technology and cannot be stored. There is only so much wind electricity that consumers in Scotland can use at any one time, and thus via the connections to Northern Ireland and England this electricity is exported.

ELSA Table 4 is a combination of ELSA Table 2 and ELSA Table 3, and so it is not discussed further in the main body of this text. Table 4 is ELSA Table 6 which combines the information from ELSA Tables 4 and 5.

\section{[Insert Table 4]}

ELSA Table 6 (shown in Table 4) contains information on both the demand side and supply side of the electricity generation sector. In the TSA there are several key aggregates which are usually reported: internal tourism expenditure and tourism direct gross value added. If we mirror these aggregates for the electricity sector we find that total electricity from generation (domestic use \& exports) expenditure in 2012 was $£ 2.2$ billion (Table 4); and electricity generation GVA was £1.4 billion (Table 5).

Other than the core tables, the development of the Scottish ELSA allows for other variables, otherwise excluded from the SNA framework, to be captured and reported. In the development of the Scottish ELSA the hourly variation in the electricity price was taken into account, meaning that the average price of electricity sold for each of the technologies can be easily calculated. At each half hourly time-step the total expenditure for a technology is given by the technology output (in MWh) multiplied by the price of the electricity - from the Nordpool database ${ }^{20}$. Summing each time-step gives the total

\footnotetext{
${ }^{20}$ See: https://www.nordpoolgroup.com/historical-market-data/.
} 
annual expenditure by each generation technology, at market prices, which we can divide by total generation by technology to give the average price of electricity. Having the average price of electricity allow us to investigate the different principles of operation of each of the different generation types. Table 5 displays the average price of electricity over the year for each generation technology.

\section{[Insert Table 5]}

The highest average price of electricity by quite some distance, is pumped storage generation. As we noted earlier this has quite unusual technical and economic characteristics, and is used mainly for providing fast-reacting generation at peak times, thus it produces electricity at times when the electricity price is the highest. Coal and gas power plants have similar average prices of electricity, perhaps this is unsurprisingly since they both have similar principles of operation and they can both vary output to meet demand.

\section{Extension of ELSA framework}

In this paper a methodology to create an electricity satellite account (ELSA) and extend the analysis of the electricity sector within the SNA frameworks has been outlined. However, rather than solely being an accounting framework there are several possible further uses and extensions of this framework. As identified in Section 2, IO models are commonly used to measure the macroeconomic impacts resulting from policy change, and there is a large literature on these models being used to identify energy-economyenvironment interactions (e.g. Chang and Lahr, 2016; Lui, 2012). 
IO models are calibrated using national/regional IO tables: an integral part of the SNA framework which typically have a single electricity sector. Due to their aggregation of generation (by types) and other electricity sector activities into a single entry, these are therefore ill-equipped for energy-economy-environmental analysis. Several authors have set out to disaggregate the electricity sector in generation and other electricity sectors activities (e.g. Gay and Proops (1993); Allan et al (2007); Weidman (2011); Linder (2013)). These sectors use two basic principles in their disaggregation - all sales for generation are to the other electricity activities sector, and generation is detailed across technologies using their shares in the overall annual generation mix.

However, as ELSA Table 5 demonstrates, the principles of operation for different technologies means that there is variation in the average price for each generation technology. In using the generation mix to allocate activity across generation types, previous studies have implicitly assumed the same average price of electricity for each technology. The information contained in the ELSA shows that this assumption can be incorrect, and a much more detailed disaggregation can now be undertaken.

It is important to reiterate though that enabling a better disaggregation of the electricity sector in the IO accounts is a consequence of the creation of an electricity satellite account. The main purpose of the creation of the ELSA is to provide information in a set of linked accounts which cannot be provided through a disaggregation of the electricity sector in the IO tables. As set out earlier, from the ELSA framework we get information on the imports of electricity from each generation source, and on the sources of electricity demand by generation type, which are not otherwise available in the IO framework. Or in the case of sources of demand by consumer type doing so in the IO framework would require disaggregation by consumer type of the demands for the output of each of the other sectors in the tables - a far from trivial undertaking. In addition, we 
can link to wider indicators relating to the activities of the sector, for example on employment and emissions, within a single coherent system of accounts.

The value in the ELSA framework is better understanding the relationship between economy and the electricity sector. However, the ELSA framework has much more information available which may be use to planners/engineers. An increasingly important part of the energy system in the transition to low carbon has been the idea of electricity management through smart grids (Tuballa and Abdundo, 2016). The development of ELSAs could aid in this as a large database is required to develop the tables and if these were created annually planners/engineers could track the changes in half-hourly demand and match with prices for use in planning of future projects.

\section{Conclusion}

The electricity sector, due to its size and role in underpinning a major portion of energy supply, is a key sector in all economies. However, it is not well represented within the internationally agreed SNA framework. Instead, all electricity activities including generation, transmission, distribution and supply are aggregated into a single sector, with the loss of important information on within sector heterogeneity. To overcome this, this paper has developed an Electricity Satellite Account (ELSA) framework, and demonstrated how these can be constructed in an application using Scottish data.

To the authors knowledge, this is the first attempt at the development of an ELSA both conceptually and practically. Satellite accounts have been used before to extend the analysis of economic sectors without interfering with the SNA framework, but never for the electricity sector. In the development we adapt the principles of TSAs - the most widely used satellite accounts - for electricity generation, and set out a clear and replicable methodology for creating such accounts. 
In the Scottish ELSA there were seven tables created, relating to (in order): imports by expenditure; domestic use by expenditure; exports by expenditure; total generated by expenditure; production account; total domestic supply; and employment. Alongwith these tables, additional data is acquired which allows for further investigation into elements of the electricity sector otherwise unidentifiable in the SNA framework, such as the average cost of a generation technology, as we have shown.

This full account gives a better understanding of the electricity sector than otherwise found within the SNA framework. In the first four ELSA tables - relating to demand - we find the expenditure of imports, domestic use, exported and generated electricity, which are lost in the highly-aggregated SNA framework. ELSA Tables 5 to 7 provide information on the supply of electricity which is otherwise unknown. Like the TSA framework, the ELSA framework can determine several key aggregates on the electricity generation sectors; such as: domestic internal electricity expenditure of $£ 1.6$ billion (ELSA Table 2), exported expenditure of $£ 0.6$ billion, taxes less subsidies on generation of $-£ 0.4$ billion (ELSA Table 6 ) and electricity generation GVA of $£ 1.4$ billion (ELSA Table 5).

In addition, while the ELSA framework allow for an improved understanding of the electricity sector within the SNA, these new accounts can also be used for other purposes. In the context of the SNA framework - the ELSA framework could be used to support the disaggregation of the electricity sector within IO accounts. In turn this could provide a richer database for a range of economic models, including Computable General Equilibrium models, to investigate major policy questions that require detailed understanding of the relationship between generation technologies and the wider economy (Linder et al, 2013). 


\section{References}

Allan, G., McGregor, P. G., Swales, J. K., \& Turner, K. (2007). Impact of alternative electricity generation technologies on the Scottish economy: an illustrative input — output analysis, Proceedings of the Institution of Mechanical Engineers, Part A: Journal of Power and Energy, 221, 243-254. http://dx.doi.org/10.1243/09576509JPE301

BEIS. (2014). Energy Consumption in the UK (2014) Chapter 5: Service sector energy consumption in the UK between 1970 and 2013. Retrieved from: Retrieved from https://www.gov.uk/government/statistics/electricity-section-5-energy-trends

BEIS. (2016). Electricity generation and supply figures for Scotland, Wales, Northern Ireland and England, 2012 to 2015. Retrieved from: https://assets.publishing.service.gov.uk/government/uploads/system/uploads/attachment _data/file/579618/Regional_Electricity_Generation_and_Supply.pdf

BEIS. (2019a). UK Energy in Brief 2019. Retrieved from: https://www.gov.uk/government/statistics/uk-energy-in-brief-2019

BEIS. (2019b). UK Offshore Wind Sector Deal. Retrieved from: https://www.gov.uk/government/publications/offshore-wind-sector-deal

BEIS (2019c). Energy Trends Electricity. Table 5.6 Imports, Exports and Transfers of electricity. Retrieved from https://www.gov.uk/government/statistics/electricity-section$\underline{\text { 5-energy-trends }}$

Clarke, J. A., Kelly, N. J., \& Tang, D. (2007). A Review of ESP-r's Flexible Solution Approach and its Application to Prospective Technical Domain Developments. Advances in Building Energy Research, 1, 227-247. https://doi.org/10.1080/17512549.2007.9687277

Chang, S., \& Lahr, M. (2016). Changes in China's production-source CO2 emissions: insights from structural decomposition analysis and linkage analysis", Economic Systems Research, 28, 224-242. https://doi.org/10.1080/09535314.2016.1172476

Elexon. 2013. Load Profiles and their use in Electricity Settlement.
Retrieved
from:
https://www.elexon.co.uk/wp-
content/uploads/2013/11/load_profiles_v2.0_cgi.pdf

Eurostat. (2008). 2008 Tourism Satellite Account: Recommended Methodological Framework ( TSA : RMF 2008 ), Statistical Commission (Vol. 39). Retrieved from https://unstats.un.org/unsd/publication/Seriesf/SeriesF 80rev1e.pdf

Ferreira, J-P. Ramons, P., Cruz, L. and Barata, E. (2018). The opportunity costs of commuting: the value of a commuting satellite account framework with an example from Lisbon Metropolitan Area, Economic Systems Research, 30, 105-119. https://doi.org/10.1080/09535314.2017.1357536

Filik, U. B., Gerek, O. N., \& Kurban, M. (2009). Hourly Forecasting of Long Term Electric Energy Demand Using a Novel Modelling Approach, Innovative Computing, Information and Control (ICICIC), 2009 Fourth International Conference On, 115-118. Rerteived from: https://ieeexplore.ieee.org/document/5412665 
Frechtling, D. C. (1999). The toursim satellite account foundations, progress and issues. Toruism Management, 20, 163-170. https://doi.org/10.1016/S0261-5177(98)00103-4

Frechtling, D. C. (2010). The toruism satellite account: A Primer. Annals of Tourism Research, 37, 136-153. https://doi.org/10.1016/j.annals.2009.08.003

Gay, P. W., \& Proops, J. L. R. (1993). Carbon dioxide production by the UK economy: An input-output assessment. Applied Energy, 44, 113-130. https://doi.org/10.1016/03062619(93)90057-V

Garton Grimwood, G., \& Ares, E. (2016). Energy: The Renewables Obligation. House of Commons Briefing Paper, (05870), 1-10. Retrieved from: https://researchbriefings.parliament.uk/ResearchBriefing/Summary/SN05870

Harrison, A. (2006). Satellite Accounts. In Fourth meeting of the Advisory Expert Group on National Accounts (pp. 1-3).

Hesmondhalgh, S. (2012). GB Electricity Demand - Initial Brattle Electricity DemandSide Model. GB Electricity Demand Project. Retrieved from: https://www.sustainabilityfirst.org.uk/images/publications/gbelec/Sustainability\%20Firs $\mathrm{t} \% 20-\% 20$ GB $\% 20$ Electricity $\% 20$ Demand $\% 20$ Project $\% 20-\% 20$ Paper $\% 202 \% 20$ \%20GB\%20Electricity\%20Demand\%202010\%20and\%202025\%20-\%202012.pdf

Ivandić N., \& Marušicś, S. (2017). Implementation of Tourism Satellite Account: Assessing the Contribution of Tourism to the Croatian Economy. Evolution of Destination Planning and Strategy, 147-171. https://doi.org/10.1007/978-3-319-42246$6 \_8$

Jones, C., \& Munday, M. (2010). Tourism satellite accounts for regions? A review of development issues and an alternative. Economic Systems Research, 22, 117-133. https://doi.org/10.1080/09535314.2010.526594

Lindner, S., Legault, J. and Guan, D. (2013). Disaggregating the electricity sector of China's input output table for improved environmental life-cycle assessment", Economic Systems Research, 25, 300-320. https://doi.org/10.1080/09535314.2012.746646

Liu, C. H., Lenzen, M., \& Murray, J. (2012). A disaggregated emissions inventory for Taiwan with uses in hybrid input-output life cycle analysis (IO-LCA), Natural Resources Forum, 36, 123-141. https://doi.org/10.1111/j.1477-8947.2012.01439.x

Leontief, W. W. (1936). Quantitative Input and Output Relations in the Economic Systems of the United States Author(s): Wassily W. Leontief. The Review of Economics and Statistics, 18(3), 105-125. https://doi.org/10.2307/1927837

Ofgem. (2012). Demand side response in the non-domestic sector. Retrieved from: http://www.element-energy.co.uk/wordpress/wp-content/uploads/2012/07/DemandSide-Response-in-the-non-domestic-sector.pdf

ONS. (2019a). UK input-output analytical table. Retrieved from https://www.ons.gov.uk/economy/nationalaccounts/supplyandusetables/datasets/ukinput outputanalyticaltablesdetailed 
ONS. (2019b). The UK Tourism Satellite Account (UK-TSA). Retrieved from https://www.ons.gov.uk/economy/nationalaccounts/satelliteaccounts/datasets/uktourism satelliteaccounttsatables

Navani, J. P., Sharma, N. K., \& Sapra, S. (2012). Technical and Non-Technical Losses in Power System and Its Economic Consequence in Indian Economy, International Journal of Electronics and Computer Science Engineering, 757-761. Retrieved from: http://citeseerx.ist.psu.edu/viewdoc/download?doi=10.1.1.436.2376\&rep $=$ rep1\&type $=p$ $\underline{\mathrm{df}}$

Ragan, A. M., \& Meis, S. (2012). Developing environmental performance measures for tourism using a Tourism Satellite Accounts approach: a pilot study of the accommodation industry in Egypt. Journal of Sustainable Tourism, 24, 1007-1023. https://doi.org/10.1080/09669582.2015.1107078

Scottish Government. (2014). Energy In Scotland 2014. Retrieved from https://www2.gov.scot/Resource/0044/00444530.pdf

Scottish Government. (2016). Energy In Scotland 2016. Retrieved from https://www2.gov.scot/Topics/Statistics/Browse/Business/Energy/EIS2016

Scottish Government. (2017). Personal correspondence with authors.

Scottish Government (2019a) Annual compendium of Scottish energy statistics. https://www2.gov.scot/Topics/Statistics/Browse/Business/Energy/ACSES

Scottish Government (2019b) Symmetric Input-Output tables. Retrieved from: https://www2.gov.scot/Topics/Statistics/Browse/Economy/Input-Output

Song, H., Dwyer, L., Li, G., \& Cao, Z. (2012). Tourism economics research: A review and assessment. Annals of Tourism Research, 39, 1653-1682. https://doi.org/10.1016/j.annals.2012.05.023

Tubulla, M. L., \& Adundo, M. L. (2016). A review of the development of Smart Grid technologies. Renewable and Sustainable Energy Reviews, 59, 710-725. http://dx.doi.org/10.1016/j.rser.2016.01.011

Wiedmann, T. O., Suh, S., Feng, K., Lenzen, M., Acquaye, A., Scott, K., \& Barrett, J. R. (2011). Application of hybrid life cycle approaches to emerging energy technologies The case of wind power in the UK. Environmental Science and Technology, 45, 59005907. https://doi.org/10.1021/es2007287 
Imported electricity expenditure (£m)

Products

Domestic $\quad \ldots . \quad$ Retail Total imports

\begin{tabular}{lccc}
\hline Coal & 3.14 & 0.77 & 7.99 \\
Gas & 2.64 & 0.65 & 6.83 \\
Nuclear & 1.54 & 0.38 & 3.90 \\
Flow & 0.06 & 0.01 & 0.15 \\
Pumped & & & \\
generation & 0.08 & 0.02 & 0.21 \\
Wind & 0.06 & & 0.16 \\
Other & 0.02 & 0.02 & 0.05
\end{tabular}


Table 2. Aggregated Table 2 of Scottish 2012 ELSA.

Domestic electricity expenditure in Scotland (£m)

\begin{tabular}{|c|c|c|c|c|}
\hline \multirow{4}{*}{ Products } & \multirow{4}{*}{ Households } & \multirow{4}{*}{.. } & \multirow{4}{*}{ Losses } & \multirow{4}{*}{$\begin{array}{c}\text { Total } \\
\text { Domestic use }\end{array}$} \\
\hline & & & & \\
\hline & & & & \\
\hline & & & & \\
\hline Coal & 117.79 & .. & 27.81 & 389.23 \\
\hline Gas & 55.79 & .. & 13.17 & 180.83 \\
\hline Nuclear & 166.87 & .. & 39.27 & 551.53 \\
\hline Flow & 47.95 & .. & 11.17 & 150.15 \\
\hline \multicolumn{5}{|l|}{ Pumped } \\
\hline Generation & 8.15 &.. & 1.77 & 26.04 \\
\hline Wind & 75.87 &.. & 19.24 & 240.62 \\
\hline Other & 20.19 &.. & 4.72 & 64.70 \\
\hline Total & 492.61 &.. & 117.16 & 1603.11 \\
\hline
\end{tabular}


Table 3. Table 3 of Scottish 2012 ELSA.

Exported electricity expenditure (£m)

Products

England Northern Ireland Total exported

\begin{tabular}{lccc}
\hline Coal & 107.98 & 23.40 & 131.39 \\
Gas & 54.72 & 11.58 & 66.30 \\
Nuclear & 148.16 & 35.38 & 183.54 \\
Flow & 49.84 & 9.62 & 59.45 \\
Pumped & 5.71 & 1.53 & 7.24 \\
Generation & 105.19 & 15.26 & \\
Wind & 19.86 & 3.99 & 120.45 \\
Other & 491.47 & 100.76 & 23.86 \\
Total & & & 592.23
\end{tabular}




\section{Supply of Scottish electricity (£m)}

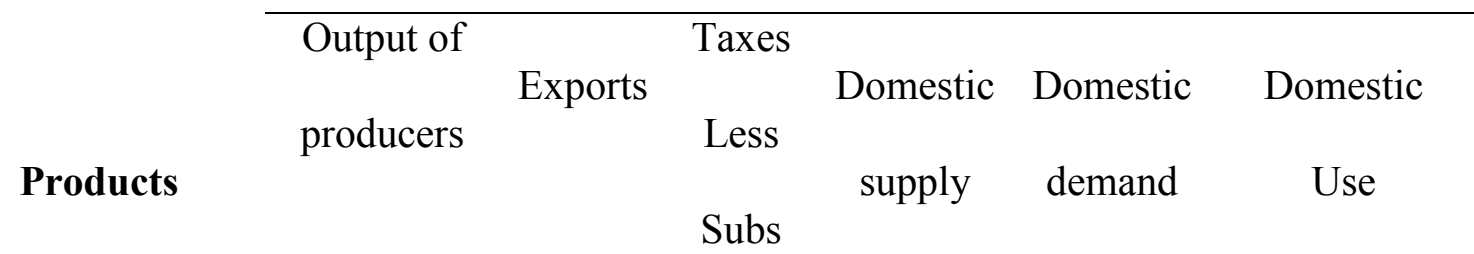

Percentage

\begin{tabular}{lrrrrrr}
\hline Coal & 243.6 & 131.4 & 0 & 412.02 & 117.8 & $48.3 \%$ \\
Gas & 111.9 & 66.3 & 0 & 193.17 & 55.8 & $49.9 \%$ \\
Nuclear & 345.4 & 183.5 & 0.0 & 528.94 & 166.9 & $48.3 \%$ \\
Flow & 91.0 & 59.5 & -128.8 & 21.68 & 47.9 & $52.7 \%$ \\
$\begin{array}{l}\text { Pumped } \\
\text { generation }\end{array}$ & 16.1 & 7.2 & -6.2 & 17.16 & 8.2 & $50.6 \%$ \\
Wind & 145.5 & 120.4 & -322.0 & -56.04 & 75.9 & $52.1 \%$ \\
Other & 39.8 & 23.9 & -17.9 & 45.75 & 20.2 & $50.8 \%$ \\
Other & & & & & & \\
electricity & 2694.7 & & & & & \\
activities & & & & & & \\
Other non- \\
electricity
\end{tabular}


Table 5. Average price electricity by technology.

\begin{tabular}{lc} 
Products & $\begin{array}{r}\text { Average price } \\
(\mathfrak{f} / \mathbf{M W h})\end{array}$ \\
\hline Coal & 46.70 \\
Gas & 46.23 \\
Nuclear & 45.53 \\
Flow & 47.14 \\
Pumped & 54.92 \\
Generation & \\
Wind & 44.31 \\
Other & 48.05 \\
Total & 46.04
\end{tabular}


Figure 1. Schematic of TSAs framework.
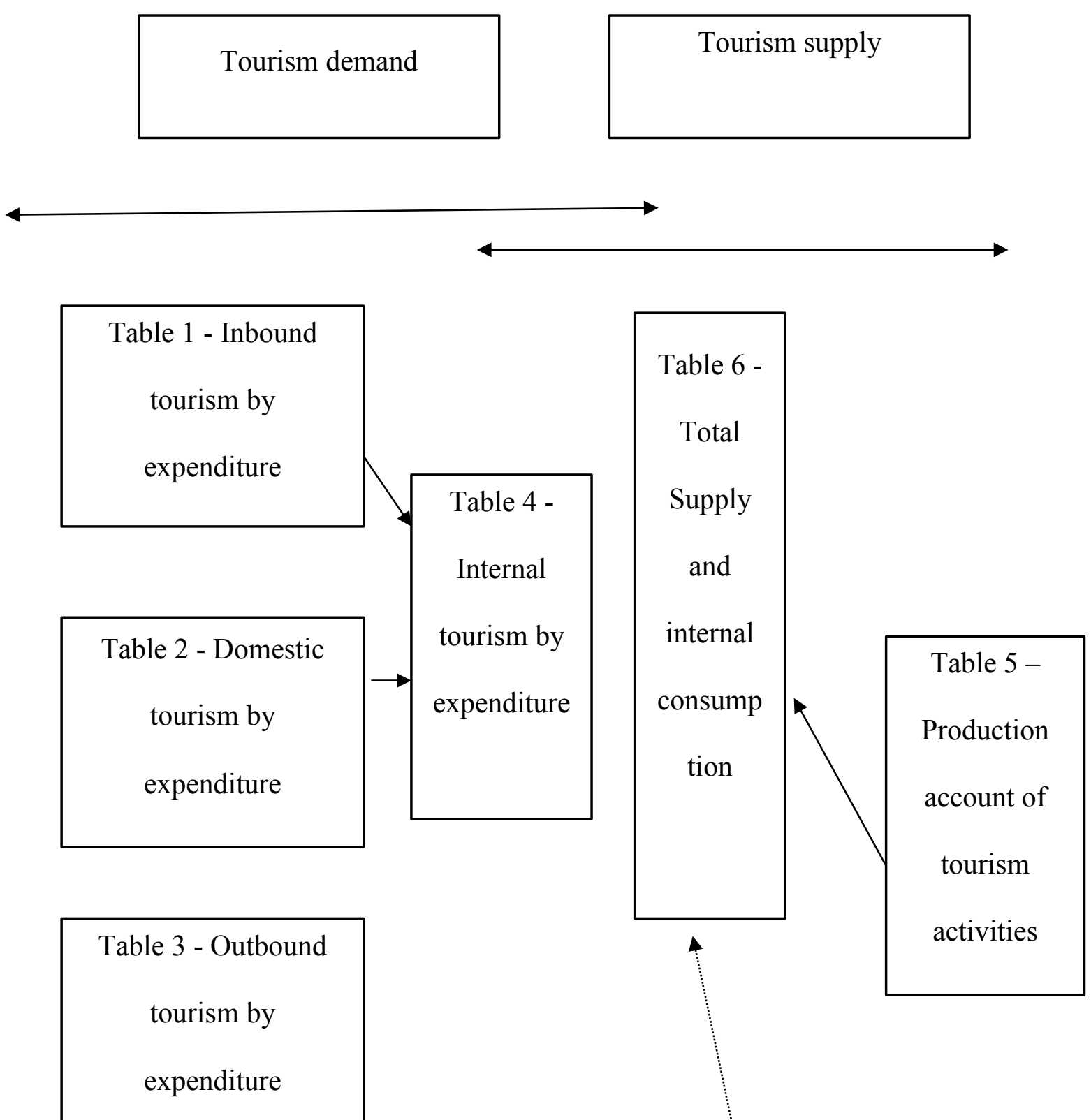

Table 3 - Outbound tourism by expenditure

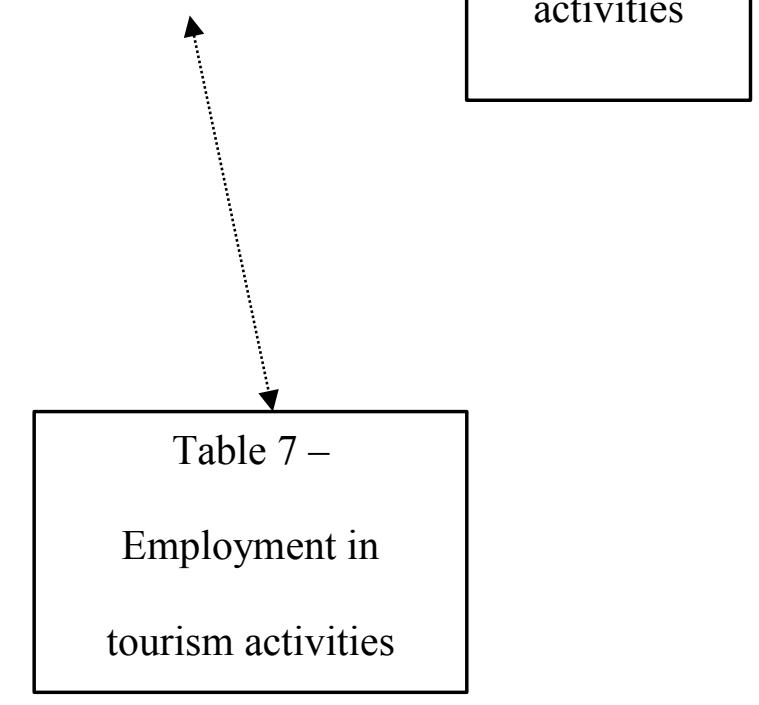


Figure 2. Schematic of ELSA framework.

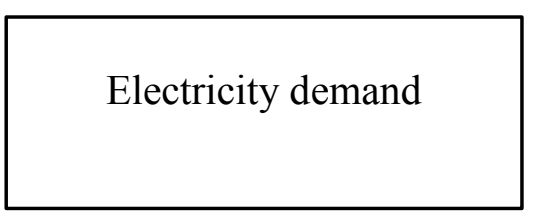

Electricity supply

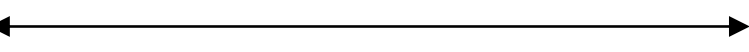

Table 1 - Imported
electricity by
expenditure

Table 3 - Exported

electricity by

expenditure

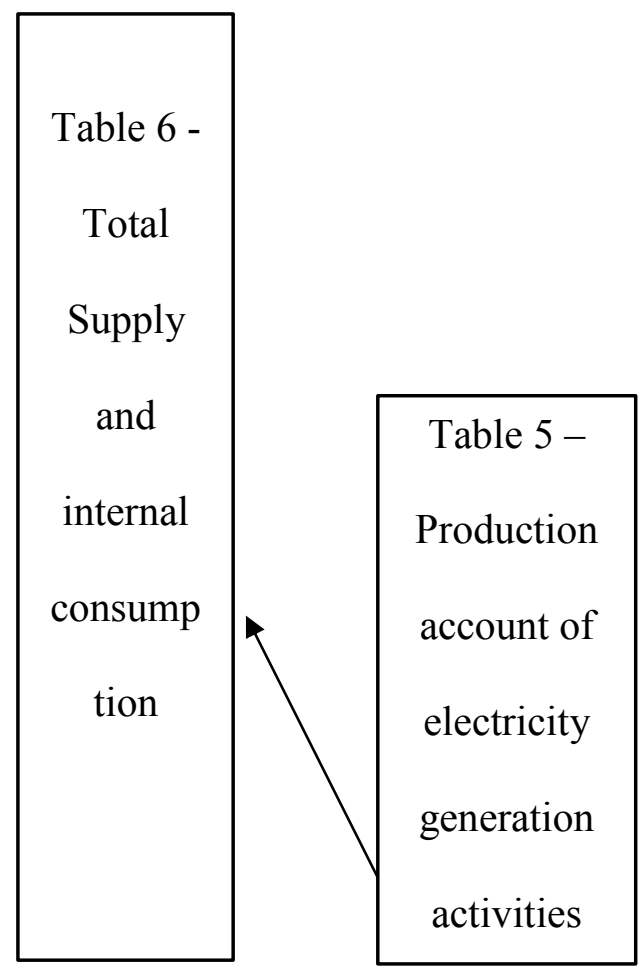

Table 7 -

Employment in

electricity activities 